\title{
The Michelangelo Phenomenon
}

\author{
Caryl E. Rusbult, ${ }^{1}$ Eli J. Finkel, ${ }^{2}$ and Madoka Kumashiro ${ }^{3}$ \\ ${ }^{1}$ Vrije Universiteit Amsterdam, ${ }^{2}$ Northwestern University, and ${ }^{3}$ Goldsmiths, University of London
}

ABSTRACT-This paper reviews theory and research regarding the "Michelangelo phenomenon." The Michelangelo model suggests that close partners sculpt one another's selves, shaping one another's skills and traits and promoting versus inhibiting one another's goal pursuits. As a result of the manner in which partners perceive and behave toward one another, each person enjoys greater or lesser success at attaining his or her ideal-self goals. Affirmation of one another's ideal-self goals yields diverse benefits, both personal and relational. The Michelangelo model and supportive empirical evidence are reviewed, the phenomenon is distinguished from related interpersonal processes, and directions for future work are outlined.

KEYWORDS_Michelangelo phenomenon; interdependence; ideal self; relationships

People have dreams and aspirations, or mental representations of the skills, traits, and resources that they ideally would like to acquire. These aspirations include diverse goals: People may want to acquire desirable traits such as warmth, confidence, or decisiveness; to achieve professional success in the form of advancement, peer respect, or financial benefits; or to advance important pursuits involving religion, travel, or athletics. Most explanations of how people acquire new skills, traits, and resources are intrapersonal, examining the individual in isolation (cf. Carver \& Scheier, 1998). But granting that people sometimes achieve desirable goals through their own actions, this personcentric approach ignores the important role that close partners play in helping people achieve their dreams and aspirations. In the following pages we review theory and research regarding the "Michelangelo phenomenon," one of the most prominent interpersonal models of how close partners promote versus inhibit each person's pursuit of ideal self goals (Drigotas, Rusbult, Wieselquist, \& Whitton, 1999).

Address correspondence to Caryl E. Rusbult, Department of Social Psychology, Vrije Universiteit Amsterdam, Van der Boechorststraat 1, 1081 BT Amsterdam, The Netherlands; e-mail: ce.rusbult@ psy.vu.nl.

\section{THE IDEAL SELF AND PARTNER AFFIRMATION}

Michelangelo Buonarroti described sculpting as a process whereby the artist releases an ideal figure from the block of stone in which it slumbers. The sculptor's task is simply to chip away at the stone so as to reveal the ideal form (Gombrich, 1995). Figure 1 depicts one of Michelangelo's unfinished captives, vividly illustrating this process. One can readily feel the force with which the ideal form strives to emerge from the stone, shedding its imperfections. The sculptor chisels, carves, and polishes the stone to reveal the ideal form slumbering within.

Humans, too, possess ideal forms. The ideal self describes an individual's dreams and aspirations, or the constellation of skills, traits, and resources that an individual ideally wishes to acquire (Higgins, 1987; Markus \& Nurius, 1986). For example, Mary's ideal self might include goals such as completing medical school, becoming more sociable, or learning to speak fluent Dutch. Whether images of the ideal self constitute vague yearnings or clearly articulated mental representations, dreams and aspirations serve a crucial function, providing direction to personal growth strivings and thereby helping people reduce the discrepancy between the actual self and the ideal self (Higgins, 1987).

Although people sometimes achieve ideal-relevant goals solely through their own actions, the acquisition of new skills, traits, and resources is also shaped by interpersonal experience. People adapt to one another during the course of interaction, changing their behavior so as to coordinate with one another and respond to each person's needs and expectations (Kelley et al., 2003). For example, John may help Mary become more sociable by subtly directing conversation during a dinner party, leading Mary to tell one of her most charming stories.

Adaptation may transpire in interactions with diverse types of partner, including romantic partners, kin, friends, or colleagues. However, adaptation is most probable, powerful, and enduring in highly interdependent relationships, in that the mutual dependence of close partners provides good opportunities for exerting strong, frequent, and benevolent influence across diverse behavioral domains (Kelley et al., 1983). Over time, adaptations that begin as temporary, interaction-specific adjustments become stable components of the self, such that over the course of extended interaction, close partners sculpt one another's selves: People come to reflect what their partners "see in them" and "elicit from them" (Rusbult \& Van Lange, 2003). 


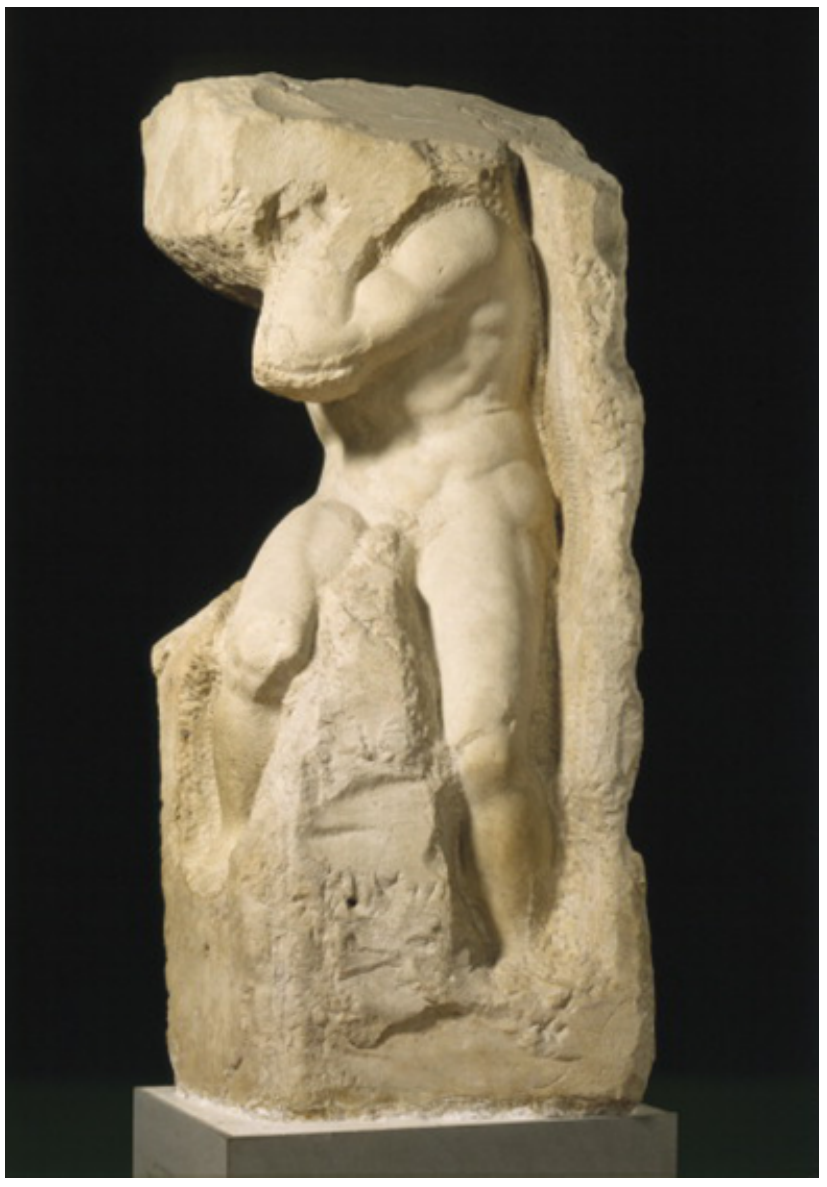

Fig. 1. Unfinished "captive" by Michelangelo Buonarroti.

Is such adaptation a good thing or a bad thing? The concept of partner affirmation describes whether the partner is an ally, neutral party, or foe in individual goal pursuits (Drigotas et al., 1999). As noted in Figure 2, affirmation has two components: Partner perceptual affirmation describes the extent to which a partner consciously or unconsciously perceives the target in ways that are compatible with the target's ideal self. For example, John may deliberately consider the character of Mary's ideal self, consciously developing benevolent interpretations of disparities between her actual self and ideal self. Alternatively, if John and Mary possess similar life goals or values, John may rather automatically perceive and display faith in Mary's ideal goal pursuits.

Partner behavioral affirmation describes the extent to which a partner consciously or unconsciously behaves in ways that elicit ideal-congruent behaviors from the target. For example, John may rather automatically communicate confidence in Mary's abilities, he may consciously or unconsciously react in a positive manner when she enacts ideal congruent behaviors, or he may provide direct assistance in her goal pursuits. Of course, John may also disaffirm Mary by communicating indifference, pessimism, or disapproval, by undermining her ideal pursuits, or by affirming qualities that are antithetical to Mary's ideal self.
The model proposes that partner affirmation yields target movement toward the ideal self (see Fig. 2): Because John affirms Mary's ideals, Mary increasingly comes to resemble her ideal self. Prior research has revealed good support for this claim. For example, in one study we videotaped married partners while they discussed a goal relevant to each person's ideal self. Trained coders rated the extent to which the partner exhibited affirming behaviors (e.g., helped target clarify plans, offered assistance, or praised goal pursuits). Four months later, we asked targets whether they had achieved the goals they discussed in the conversations. Analyses revealed that when partners were more affirming during goal-relevant conversations, targets were more likely to achieve their ideal-self goals (Rusbult, Coolsen, et al., 2009).

In another study we asked pairs of friends to provide complementary questionnaire data wherein (a) one friend served as "target," rating his or her own experiences of partner affirmation and target movement (how affirming is your dating partner?; how successful are you at your goal pursuits?), and (b) the second friend served as "observer," also rating partner affirmation and target movement (how affirming is the target's dating partner?; how successful is the target at his or her goal pursuits?). Analyses revealed sizable across-friend associations-for example, when friends (as observers) described the target's partner as highly affirming, individuals themselves (as targets) reported greater movement toward their ideal selves (Drigotas et al., 1999).

Of what consequence is the Michelangelo phenomenon? Growth striving is a primary human motive (cf. Deci \& Ryan, 2000) - a motive that is directly gratified by movement toward the ideal self. Accordingly, when a partner is affirming and a target moves closer to his or her ideals, the target enjoys enhanced personal well-being, including greater life satisfaction and psychological health (e.g., Drigotas, 2002). Moreover, when a partner serves as an ally in promoting target growth, the target enjoys enhanced couple well-being, including greater adjustment and probability of persistence (e.g., Drigotas et al., 1999; Kumashiro, Rusbult, Finkenauer, \& Stocker, 2007).

\section{PARTNER AFFIRMATION AND RELATED INTERPERSONAL PROCESSES}

\section{Partner Enhancement}

In what ways does partner affirmation differ from related interpersonal processes? To begin with, how does partner affirmation relate to partner enhancement, which describes the extent to which a partner perceives the target and behaves toward the target in ways that are more positive than may be "realistically" warranted-for example, in a manner that is more positive than the target perceives the self. Numerous studies have revealed that partner enhancement is beneficial to individuals and to relationships: For example, when partners perceive one another more positively than each person perceives himself or herself, relationships exhibit superior functioning (e.g., Murray, Holmes, \& Griffin, 1996). 
The Michelangelo Phenomenon

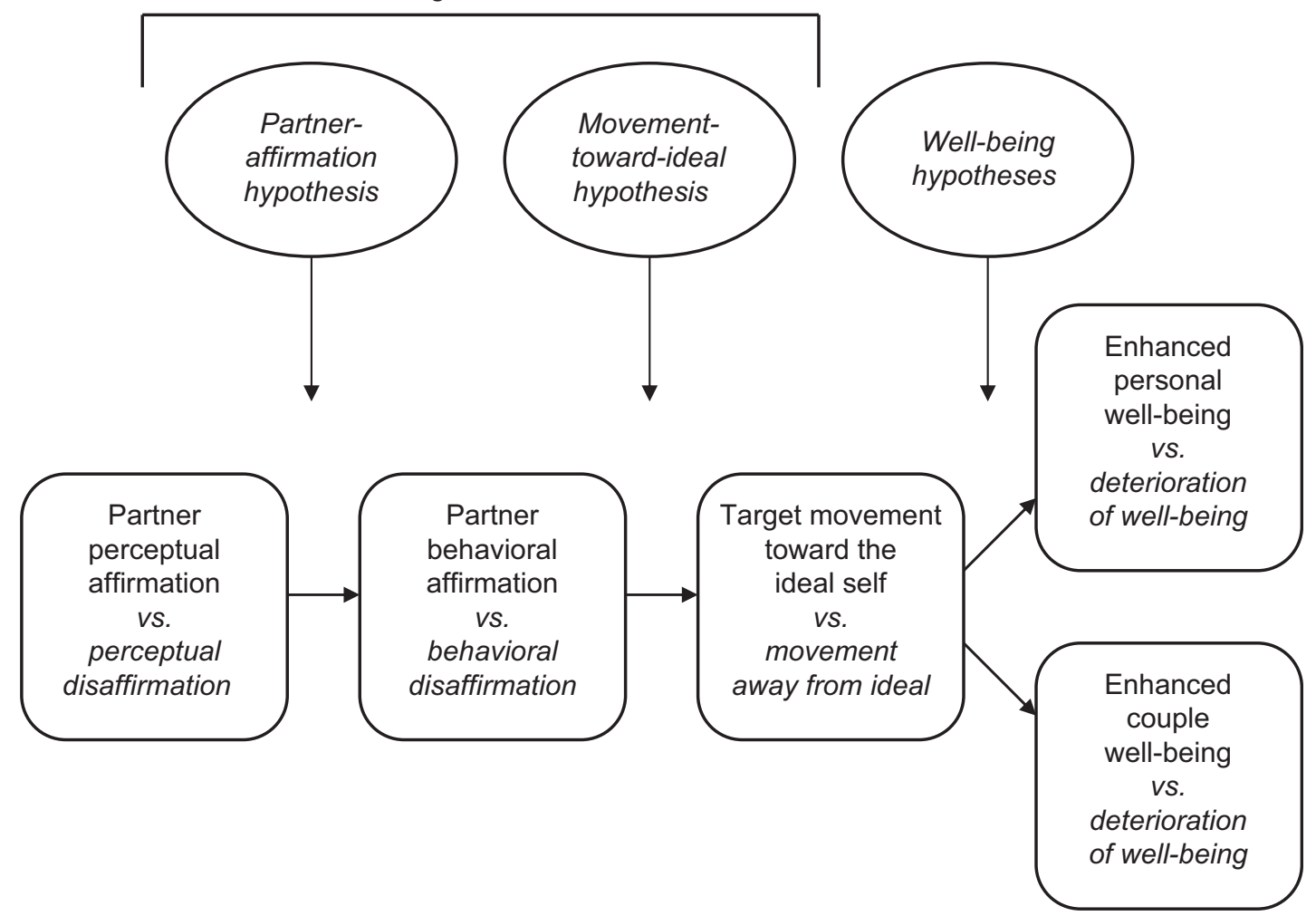

Fig. 2. The Michelangelo phenomenon, personal well-being, and couple well-being. Partner perceptual affirmation promotes partner behavioral affirmation (partner-affirmation hypothesis), partner behavioral affirmation promotes target movement toward the ideal self (movement-toward-ideal hypothesis), and target movement toward the ideal self promotes personal well-being and couple well-being (well-being hypotheses).

Are all forms of enhancement equally beneficial, or is enhancement more fruitful for some sorts of target skills and traits than for others? In particular, are positive partner thoughts and acts most helpful to the extent that they concern attributes that are part of the target's ideal self? We conducted several studies to pit two forms of partner positivity against each other-normative positivity (general social desirability) versus ideal positivity (relevance to the target's ideal self).

In one study, we asked participants to rate 25 personal attributes (e.g., warm/cold, talkative/reserved) with respect to (a) normative positivity, or whether each attribute was widely considered desirable for people of the target's age and sex; (b) ideal positivity, or whether each attribute was an element of the target's ideal self; and (c) partner behavior, or whether the partner's thoughts and actions promoted each attribute (e.g., Drigotas et al, 1999). We developed within-participant, correlation-based measures of normative partner positivity (correlation of normative ratings with ratings of partner behavior) and ideal partner positivity, or partner affirmation (correlation of ideal-relevant ratings with ratings of partner behavior). In predicting both target movement toward ideal and couple well-being, ideal positivity trumped normative positivitythat is, partner affirmation accounted for significant variance whereas normative partner positivity did not.
For example, assume that Mary ideally wants to become physically fit. It may be pleasant when John exhibits exceedingly positive behavior with respect to qualities that are normatively desirable, yet not part of her ideal self-for instance, by praising her taste in clothes-but she will derive far greater gratification when John exhibits positivity with respect to qualities that are core elements of her ideal self, such as her exercise plan. In short, partner enhancement would seem to be most beneficial when "enhancement" takes the form of affirmation: when partners are exceptionally positive with respect to attributes that are core elements of what each person ideally wishes to become.

\section{Partner Verification}

How does partner affirmation operate in conjunction with partner verification, which describes the extent to which a partner perceives and behaves toward the target in ways that are consistent with the target's beliefs about his or her actual self? Numerous studies have revealed that partner verification is beneficial: For example, when a partner behaves toward the target in a manner that is congruent with how the target perceives his or her actual self, couple well-being is enhanced (cf. Swann, DeLaRonde, \& Hixon, 1994). Interestingly, verification en- 
hances couple well-being not only among targets with high selfesteem (whose partners verify by perceiving them positively) but also among targets with low self-esteem (whose partners verify by perceiving them negatively).

If it is beneficial for a partner to perceive and support the target's beliefs about the actual self, how can it also be beneficial for a partner to perceive and support the target's ideal self? To address this issue, we conducted several studies to examine the simultaneous effects of partner affirmation and partner verification. Two findings from this work are noteworthy: First, affirmation and verification are not incompatible: It is possible for a partner to not only promote the best in a target (to affirm) but also to perceive and support the target's perception of his or her actual self (to verify; e.g., Kumashiro et al., 2009). Second, both affirmation and verification account for unique variance in key model variables.

Why is it beneficial for a partner to simultaneously exhibit affirmation and verification? We propose that to effectively sculpt a block of stone, the sculptor must not only understand the ideal form slumbering in the block but must also understand the block per se-what possibilities are inherent in the block and what flaws must be circumvented. For example, to effectively affirm Mary, John must exhibit a nuanced set of behaviors that not only affirms her ideal self (what is the ideal form?) but that also verifies her actual self (what is the nature of the block of stone?), including not only (a) understanding how Mary's actual skills and traits might best be employed to achieve ideal-self goals, but also (b) understanding how Mary perceives herself and addressing problems and opportunities therein (e.g., acknowledging yet bolstering low self-regard, correcting unrealistic perceptions).

\section{Pygmalion Phenomenon}

What happens when a partner affirms qualities that are elements of his or her own ideal self? The "Pygmalion phenomenon" describes a partner who perceives and behaves toward the target in ways that are consistent with the partner's own ideal self (irrespective of the target's ideal self). Research reveals that the Pygmalion phenomenon is negatively associated with diverse indices of personal and couple well-being (e.g., Rusbult, Kumashiro, Finkel, et al., 2009). Thus, although a partner may believe that he or she knows better than the target what is "good for" the target, his or her behavior is unlikely to be productive if those construals deviate from the target's own ideal self. In short, it is unwise to foist one's own ideal-self representations onto others. To be effective, partner affirmation must be oriented toward key elements of the target's ideal self.

\section{CONTEMPORARY RESEARCH AND DIRECTIONS FOR THE FUTURE}

In the spirit of the Michelangelo metaphor, in contemporary work we have examined properties of the sculptor (partner), sculpture (target), and their relationship that promote versus inhibit the Michelangelo phenomenon. First, we have examined individual differences in goal pursuit traits, demonstrating that target and partner traits exert both direct and indirect effects on each person's behavior: As a product of both persons' traits, some targets are easier than others to sculpt, and some partners exhibit more effective sculpting than others (e.g., Kumashiro et al., 2007). Second, we have examined how ideal similarity shapes the Michelangelo process, demonstrating that when partners actually possess key elements of the target's ideal self, partners are more affirming and targets exhibit greater movement toward their ideals (Rusbult, Kumashiro, Kubacka, \& Finkel, 2009). And third, we have examined how partner affirmation influences relationships, demonstrating that affirmation promotes perceived responsiveness, or target belief that the partner understands the target, approves of the target, and genuinely cares about the target's well-being. In turn, perceived responsiveness promotes trust in the partner and strengthens target commitment (Rusbult, Reis, \& Kumashiro, 2009).

At least three avenues might be particularly fruitful in future work: First, despite the success of our initial endeavors, much remains to be learned about properties of the sculptor, sculpture, and their relationship. For example, is the Michelangelo phenomenon enhanced when a target possesses clearly articulated ideal-self goals, or to the extent that partners possess similar implicit theories of personality? Second, it is important to explore the conditions under which the phenomenon may unfold unconsciously or rest on automatic processes. For example, if John is to sculpt effectively, when must he possess conscious knowledge of Mary's ideal self and develop deliberate strategies for affirming her ideals, and when does the process rest on relatively more automatic, habitual processes? A third promising direction for the future involves examining self representations other than the ideal self. For example, does affirming ought-self goals (duties and responsibilities) promote personal and relational well-being, paralleling the observed benefits of affirming ideal-self goals (dreams and aspirations; Higgins, 1987)?

\section{CONCLUSIONS}

Most work regarding goal pursuit has examined individuals toiling in isolation. The Michelangelo phenomenon model integrates concepts from the interdependence tradition and the self tradition to illuminate the means by which close partners promote versus inhibit one another's movement toward ideal-self goals. As posited by the model, it appears that the self is indeed a socially constructed entity (cf. Cooley, 1902): Close partners sculpt one another's selves, shaping one another's skills and traits and promoting versus inhibiting one another's goal pursuits. To be sure, people sometimes make significant progress toward achieving their goals via autonomous, individual action. However, an ally in this process is invaluable, particularly when the ally is a gifted sculptor. 


\section{Recommended Readings}

Drigotas, S.M., Rusbult, C.E., Wieselquist, J., \& Whitton, S. (1999). (See References). The initial publication regarding the Michelangelo phenomenon model, presenting evidence in support of key model predictions, using diverse methods and measurement techniques.

Kumashiro, M., Rusbult, C.E., Wolf, S., \& Estrada, M.J. (2006). The Michelangelo phenomenon: Partner affirmation and self movement toward one's ideal. In K. Vohs \& E. Finkel (Eds.), Intrapersonal processes and interpersonal relationships: How they relate. (pp. 317-341). New York: Guilford. Chapter providing a relatively recent and reasonably comprehensive review of research regarding the Michelangelo phenomenon model.

Rusbult, C.E., Kumashiro, M., Kubacka, K.E., \& Finkel, E.J. (2009). (See References). Empirical article presenting evidence that when partners actually possesses key elements of the target's ideal self, partners are more affirming and targets exhibit greater movement toward their ideals.

Acknowledgments - This research was supported by research grants to the first author from the National Science Foundation (BCS-0132398), the Templeton Foundation (No. 5158), the Fetzer Institute, and the Vrije Universiteit Amsterdam (Bruidschat Award), and by a grant to the second author from the Netherlands Organization for Scientific Research (NWO-04011-020).

\section{REFERENCES}

Carver, C.S., \& Scheier, M.F. (1998). On the self-regulation of behavior. New York: Cambridge University Press.

Cooley, D.H. (1902). Human nature and the social order. New York: Scribners.

Deci, E.L., \& Ryan, R.M. (2000). The "what" and "why" of goal pursuits: Human needs and the self-determination of behavior. Psychological Inquiry, 11, 227-268.

Drigotas, S.M. (2002). The Michelangelo phenomenon and personal well-being. Journal of Personality, 70, 59-77.

Drigotas, S.M., Rusbult, C.E., Wieselquist, J., \& Whitton, S. (1999). Close partner as sculptor of the ideal self: Behavioral affirmation and the Michelangelo phenomenon. Journal of Personality and Social Psychology, 77, 293-323.
Gombrich, E.H. (1995). The story of art (16th ed.). London: Phaidon Press.

Higgins, E.T. (1987). Self-discrepancy: A theory relating self and affect. Psychological Review, 94, 319-340.

Kelley, H.H., Berscheid, E., Christensen, A., Harvey, J.H., Huston, T.L., Levinger, G., et al. (Eds.). (1983). Close relationships. New York: W. H. Freeman.

Kelley, H.H., Holmes, J.G., Kerr, N.L., Reis, H.T., Rusbult, C.E., \& Van Lange, P.A.M. (2003). An atlas of interpersonal situations. New York: Cambridge University Press.

Kumashiro, M., Rusbult, C.E., Coolsen, M.K., Wolf, S.T., van den Bosch, M., \& van der Lee, R. (2009). Partner affirmation, verification, and enhancement as determinants of attraction to potential dates: Experimental evidence of the unique effect of affirmation. Unpublished manuscript, Goldsmiths, University of London.

Kumashiro, M., Rusbult, C.E., Finkenauer, C., \& Stocker, S.L. (2007). To think or to do: The impact of assessment and locomotion orientation on the Michelangelo phenomenon. Journal of Social and Personal Relationships, 24, 591-611.

Markus, H., \& Nurius, P. (1986). Possible selves. American Psychologist, 41, 954-969.

Murray, S.L., Holmes, J.G., \& Griffin, D.W. (1996). The benefits of positive illusions: Idealization and the construction of satisfaction in close relationships. Journal of Personality and Social Psychology, 70, 79-98.

Rusbult, C.E., Coolsen, M., Kirchner, J., Stocker, S., Kumashiro, M., Wolf, S., et al. (2009). Partner affirmation and target movement toward ideal in newly-committed relationships. Unpublished manuscript, Vrije Universiteit Amsterdam.

Rusbult, C.E., Kumashiro, M., Finkel, E., Kirchner, J., Coolsen, M., Stocker, S., \& Clarke, J. (2009). A longitudinal study of the Michelangelo phenomenon in marital relationships. Unpublished manuscript, Vrije Universiteit Amsterdam.

Rusbult, C.E., Kumashiro, M., Kubacka, K.E., \& Finkel, E.J. (2009). The part of me that you bring out: Ideal similarity and the Michelangelo phenomenon. Journal of Personality and Social Psychology, 96, 61-82.

Rusbult, C.E., Reis, H.T., \& Kumashiro, M. (2009). On the regulation of ongoing relationships: Partner affirmation, perceived responsiveness, and mutual cyclical growth. Unpublished manuscript, Vrije Universiteit Amsterdam.

Rusbult, C.E., \& Van Lange, P.A.M. (2003). Interdependence, interaction, and relationships. Annual Review of Psychology, 54, 351-375.

Swann, W.B. Jr., DeLaRonde, C., \& Hixon, J.G. (1994). Authenticity and positivity strivings in marriage and courtship. Journal of Personality and Social Psychology, 66, 857-869. 